\title{
ENSAIOS
}

\section{A ÉTICA NA CULTURA E NA ESCOLHA}

\section{RESUMO}

Este ensaio tem por objetivo refletir sobre a administração da cidade e a preservação de práticas culturais organizacionais que legitimam ações na dinâmica da ética na cultura. Analisam-se, especificamente, as escolhas feitas pela família e as repercussões na vulnerabilidade da segurança do cidadão na cidade. As reflexões teóricas recorrem a Serres (2003, 1997a, 1997b, 1990), sobre a cidadania como ética e o parasita na sociedade; à metodologia e teoria para análise das culturas de Durand (2008, 2002); a proposta mitohermenêutica de Ferreira-Santos (2004), um parâmetro para práticas sociais e educativas hermesianas, mediadoras, e estudos e pesquisas mitohermenêuticas de Sanches sobre a interculturalidade na educação (2011, 2010a, 2010b). Nos resultados encontrados, tendo por um lado as pressões institucionais, sociais, pela responsabilidade política e moral da família, e por outro, a simbologia manifesta na dinâmica da cultura, as práticas de princípios éticos são banalizados, assim como é ignorado o olhar ingênuo na construção da cidadania e no tipo de percepção da responsabilidade pelas consequências das escolhas feitas.

Palavras-chave: Gestão da cidade. Ética. Cultura. Cidadania.

\section{INTRODUÇÃO}

O que é a ética senão aquilo que um grupamento humano considera "o correto" em um determinado espaço e tempo histórico? O que são os símbolos que transitam em um sistema social, senão o resultado das pressões exercidas pelas condições políticas, econômicas, culturais sobre o grupo humano? Conhecer sobre a ética escolhida para viver, considerando ainda que, nesse processo, nem tudo é uma escolha, - é o objetivo deste ensaio, assim como refletir sobre a trajetória antropológica, a participação política e moral da família, analisar especificamente a força conservadora da dinâmica da ética familiar e suas consequências quanto à

Janina Mirtha Gladys Moquillaza Sanchez janinasanches@gmail.com Pós-Doutora em Filosofia da Antropologia da Educação Universidade de São Paulo FE-USP, SP-BR vulnerabilidade da segurança dos cidadãos na cidade.

Adotando o parâmetro mitohermenêutico para práticas sociais e educativas de Ferreira-Santos (2004), a metodologia e a teoria para análise das culturas, de Durand (2008, 2002), as ideias de Serres (2003, 1997a, 1997b, 1990) sobre a cidadania como ética e o parasita na sociedade, esta meditação é também uma construção 
mitohermenêutica (SANCHES, 2011, 2010a, 2010b) sobre as escolhas feitas pelo indivíduo e pelo grupamento social na vida coletiva.

A colaboração de dois grupos de estudantes de um Centro Universitário particular do Ceará, que atuaram como copesquisadores ${ }^{1}$, foi definitivo para desvelar desigualdades e formas de controle social perversos. Encontramos antagonismos, manipulações e conivências no modo de participação social, pois em oposição ao estabelecido pela Constituição de 1988, Artigo 5, a referência moral do sistema não se posiciona na defesa da cidadania, mas participa sub-repticiamente em jogos de poder.

O processo iniciou-se com os alunos assistindo ao filme "O Som ao Redor" do diretor pernambucano Kleber Mendonça Filho, 2013, sobre mudanças que aconteceram na vida de famílias de um bairro de classe média de Recife a partir da chegada de um grupo de milícia, que ofereceu o serviço de proteção particular às pessoas do bairro. Das aproximações crítico-sociais do filme, os alunos decidiram tomar para foco da pesquisa a cumplicidade da família com o membro infrator, fazendo um paralelo com a realidade vivida atualmente em Fortaleza.

No filme, a cumplicidade é observada no personagem do velho e rico proprietário de imóveis que recebeu os milicianos e os autorizou a fazer seu trabalho no bairro, desde que não incomodassem seu neto, jovem que vagava em seu quarto, entre os aposentos da família, em casas de amigos, pelas ruas, e que costumava roubar o som de carros estacionados nas redondezas.

Uma vez que os alunos-pesquisadores escolheram os sujeitos de estudo e pesquisa, construíram e aplicaram um questionário entre os colegas e outros frequentadores do Centro Universitário; o resultado revelou o que nos pareceu ser a escolha ética da família, de não impedir a corrupção ( $85 \%$ de 180 respostas), instaurando o conflito moral quanto a impedir, ou não impedir (educar?) o infrator $(59 \%$ de 108 respostas) no âmbito da família.

Dos resultados encontrados, observamos na trajetória antropológica, por um polo, as pressões institucionais, sociais, a qualidade de responsabilidade política e moral da família, e por outro, a simbologia manifesta na dinâmica da cultura, as práticas de princípios éticos banalizados, assim como um olhar ingênuo na construção da cidadania e no tipo de percepção da responsabilidade pelas consequências das escolhas feitas.

\section{POR QUE TROCAR DE LUGAR PARA VER O MESMO FENÔMENO?}

Qual a perspectiva adotada para perceber o movimento da ética? No âmbito familiar, como se constrói o compromisso moral? Compreendendo que o mito é fundador da vida em sociedade, da dinâmica dos símbolos que resultam numa narrativa histórica relativamente estável (DURAND, 2002) e, querendo refletir sobre a organização das imagens éticas culturais em nosso meio, em Fortaleza, ou, pelo método de convergência, observar a "constelação de imagens" ou modelos taxionômicos, didático-pedagógicos e de gestão que daí resultam, configurando imagens do Regime Noturno, ou seja, a estrutura arquetípica do culto e veneração da figura primordial da mãe, a própria água que lava, mas também é veículo da tinta, torna-se espessa nas cores verde e violeta, inspirando amor e horror ao mesmo tempo que suga e preserva tudo e todos em seu redor, sendo primordial matéria do mistério (DURAND, 2002).

Quanto ao personagem do neto autorizado a roubar, busquei, em meu acervo mitológico, a figura arquetípica daquele que toma tudo e não dá nada em troca. Haveria um deus depredador, que toma sem devolver? Que usa do outro sem dar nada em troca? Acostumada a transitar pela excelência dos deuses gregos e romanos, saudáveis, fortes, com exceção de Hefaístos, que manca e Aquiles, com seu vulnerável calcanhar, mas também acostumada a buscar de outras fontes, encontrei que é nas mitologias alemã, francesa e especialmente nas latino-americanas, que habitam deuses monstruosos e, ali, o invalidismo tem maior importância (GUGGENBÜHL-GRAIG，1998): são personagens sem uma perna - Long John Sil- 
ver, Saci Pererê; sem um braço - Capitão Gancho; sem um olho - Pirata, lembrando-nos que somos imperfeitos.

Quanto ao invalidismo, esse não leva a parte alguma, nem à morte, nem à saúde, pois é deficiência crônica, duradoura, um estado crônico de estar fora de ordem e depender de ser dependente (GUGGENBÜHL-CRAIG, 1998). No lado oposto e complementar ao mesmo arquétipo, alimentando a fantasia e a dificuldade em aceitar nossas limitações e deficiências, a mídia, a publicidade, as redes sociais construindo e fomentando os seres perfeitos que deveríamos ser, os (as) deuses(as) perfeitos (as), belos(as), rostos perfeitos, pele perfeita, olhos perfeitos, cabelos perfeitos, altura perfeita, compleição do corpo perfeito, trabalhadores perfeitos que não erram jamais, contando com milhares de amigos perfeitos.

Quanto aos estudantes universitários, ao relacionar o estudo à sua realidade em Fortaleza, eles lançaram a hipótese de que a família seria conivente com o infrator, como se confirmou pelos resultados da pesquisa quantitativa. De imediato, eles estavam falando de uma narrativa moral conhecida e relegando para outra reflexão, mais aprofundada e possivelmente dolorosa, as implicações dessa semântica, as possibilidades de análise crítica sobre como está ocorrendo a construção da cidadania e da consciência da liberdade de escolha, pois como já defendeu Bauman (2007), atualmente, a capacidade de uma pessoa ser consumidor e devedor, e não de ser produtor, é o que define o seu status de cidadão.

No caso da vida do inconsciente familiar (SZONDI, 1970) aqui analisada, não sendo uma herança fixa, mas podendo transformar a sua moral pelos mecanismos de defesa ao longo de toda a vida e ampliando-se, pode, assim, ganhar outras dimensões, diferentes do modelo originalmente conhecido (SERRES, 1997a). Caberia, então, a conscientização sobre não entregar-se à ingenuidade, ao consumismo, e à violência do parasitismo? Não somente pela vida inativa crônica do indivíduo, mas por investir contra as possibilidades da espécie hu- mana de ser ativo. Não entregar-se à violência, especialmente em espírito, pois ultrapassando a consciência e as intenções, ele se transforma em poderoso multiplicador (SERRES, 2003).

A dimensão do espírito, o mundo das ideias, o meio universitário, com cientistas, administradores, engenheiros, tecnólogos, comunicadores, inventores, arquitetos, médicos, enfermeiros, escritores, filósofos, inovadores das diversas áreas do conhecimento, trabalhadores na gestão daquilo que é direito público, tarefa das políticas públicas, do fazer justiça ao ser humano. Profissionais da gestão do espaço público, que adotariam um princípio de cidadania como ética, tendo a obrigação moral de evitar fazer o mal (SERRES, 1997a), embuídos da tarefa de compreender as pessoas, os seres vivos, não vivos, e de outras espécies, na diversidade de suas diferenças.

Quanto à experiência empírica da pesquisa objeto desta reflexão, o resultado às questões propostas pelos alunos da turma da noite, 2014.1, foram as seguintes respostas obtidas em 108 formulários aplicados:

a) você acha que quando há um infrator na família cearense, a família se reúne para impedi-lo?

- 59.3\% afirmaram que não, a família não interfere diante de um infrator;

b) na sua família, se você soubesse que alguém está prestes a cometer algo negativo:

- você ficaria calado? 90,7\% afirmaram que não ficariam calados;

- você o aconselharia? $87,9 \%$ disseram que aconselhariam o parente comprometimento baixo;

- você o impediria? $62 \%$ tomaria a atitude efetiva de propor-se a impedir que a infração fosse concretizada; - você o denunciaria? 53.7\% não se propuseram a denunciar.

Na turma da manhã, 2014.1, tendo aplicado 180 formulários, encontrou-se que:

a) quando ocorre corrupção (ativa ou passiva) na família, ela se reúne para impedí-la? - $85.5 \%$ responderam que não. 
b) em sua família, se você soubesse que alguém está para cometer um ato corrupto.

- você se calaria? $74.4 \%$ disseram que não.

- você o aconselharia? $83.3 \%$ disseram que sim (comprometimento baixo).

- você o impediria? $58.8 \%$ disseram que sim.

- você o denunciaria? $53.8 \%$ disseram que não.

De acordo com esses resultados e o debate com os alunos, a família, temerosa, tende a ser conivente com o infrator e com o corruptor. Contraditória, a moral conservadora requer a proteção familiar, a qualquer custo. $\quad \mathrm{N}$ a análise mito-hermenêutica, tendo esta reflexão começado pela experiência empírica e tendo encontrado uma estrutura antropológica do tipo Regime Noturno (DURAND, 2002), ou seja, materno, engolidor, possuidor, conservador, de morte, pelo tempo preservado na intimidade do cego aconchego, observamos em oposição paradoxal a comemoração do nascimento, do plural, a alegria de viver, o simbolismo lunar polivalente, hermafrodito e a festa, comemorações rotineiras; sendo, ao mesmo tempo, da ordem do negativo, em que as normas são abolidas, desrespeitadas, burladas, enquanto se dá a promessa de uma ordem vindoura .

O contexto cultural fala de si mesmo: na cultura cearense conservadora, os fins de semana são dedicados aos encontros em família, aos amigos e à igreja. Por contradição, na lógica organizacional da gestão da cidade onde moram aproximadamente dois milhões e meio de pessoas e em que cerca de novecentos mil automóveis transitam pelas ruas, a organicidade dos fluxos ocorre com enorme dificuldade, buzinas poluem o espaço público por motivações torpes; batidas entre automóveis, motos e bicicletas são frequentes e graves infrações à sinalização de trânsito são cometidas a todo momento, pois é comum transitar-se na contra mão. Pedestres atravessando no meio da avenida, ciclistas ignorando a sinalização dos semá- foros, automóveis desafiando a sorte nos cruzamentos e acidentes com lesões graves e morte, são comuns. Como se não houvesse normas, educação pública para a vida no espaço coletivo e direitos do (a) cidadão (ã).

Nas práticas, independentemente de vínculos ideológicos, sente-se a falta das ações do tipo crepusculares, como batizou Ferreira-Santos (2003), aquelas de caráter chamado hermesiano, do mediador, que conversa em dialogia, percebendo as multilógicas em suas contradições. Embora saibamos que acontecem diálogos silenciosos, reflexivos, pelos espaços filosóficos, artísticos e hipertextos da cidade, eles lutam, no entanto, por um espaço maior na construção diária, frequente, da autopoiése da construção da cidadania.

"O velho sábio, sem saber, colocou frente a frente, os dois únicos jogos em que as partes ganham juntas: jogos proibidos pela história e pela sociedade, que só cessam ao premiarem com a morte os jogos sórdidos que resultam em nada", já lembrava Serres (1990, p. 74).

Perguntando aos alunos copesquisadores por que a família não impede o infrator, a resposta foi "é assim mesmo, ninguém se mete", e disseram também "as famílias temem a prisão". Os mesmos participantes trouxeram a noção do individualismo socialmente vivido e o temor à "prisão", como se não houvesse outras instâncias de recuperação social do infrator, anteriores à prisão, nas quais o cidadão pudesse e devesse confiar. Mantida na ingenuidade, a responsabilidade social moral é tratada como se não tivesse visibilidade e não fizesse parte da projeção sócio-cultural.

Carregada de eufemismo, a perspectiva familiar precisaria mudar de lugar. Adotar uma nova posição pela qual the fosse possível olhar para o mesmo fenômeno sob a perspectiva crítica que lhe permitisse visualizar estrategicamente a recursividade de suas ações (MORIN, 2007) e a responsabilidade pelas consequências das escolhas sociais feitas. 


\section{CONSIDERAÇÕES FINAIS}

$\mathrm{O}$ fato de este ensaio-reflexão ter começado pela experiência, em uma atmosfera antropológica chamada Noturna, portanto conservadora, sugadora, encontra por oposição, na mesma constelação de imagens, a dinâmica do renascimento que se faz presente, a alegria coletiva constante, o som alto do forró, em contraposição ao individualismo arrogante protegido pelos vidros escuros de óculos importados e das janelas de automóveis importados que transitam imperiosos pelas ruas mal asfaltadas e mal sinalizadas. Encontra-se no ambiente educativo a necessidade de participar, de ser aceito, admitido pelos parceiros, pelos colegas, professores, pelos pares, redundando em submissão.

Nas relações interpessoais, determinantes para o ser humano, desvelam-se antagonismos históricos não resolvidos, rejeição ou negação de determinados grupos sociais, como é o caso dos povos nativos e quilombos, assim engendrando dificuldades em manter a fidelidade aos parceiros, à família, às associações e em casos extremos, levando à depressão (relógios digitais nas calçadas praianas da cidade anunciam atendimento anônimo à depressão).

A importância em destacar as figuras comuns do professor e da família, deve-se à necessidade de valorização do seu protagonismo nas práticas de gestão da cidade, da qual todos fazem parte. Na procura de possibilidades de construção de melhor gestão da cidade, a integração pelo envolvimento na exploração científica, a procura por novos focos de curiosidade, a participação em atividades coletivas de pesquisa de campo e colaboração com as comunidades de risco e vulnerabilidade, a participação em debates sobre a realidade da segurança coletiva, assim como socioambientais e da saúde, a produção de estudos aprofundados e pesquisas sobre a qualidade de vida humana em novos espaços antropológicos e na relação com outras espécies, são possibilidades de compartilhamento e de assumir responsabilidades na busca de acerto.

Observar que as ações éticas transformam para um bem maior, tornam-se fato impor- tante na construção da história pessoal, assim como da história coletiva, encorajam a expor a redundância de comportamentos considerados corretos (ou não), respeitosos nos momentos em que as pessoas costumam resolver impasses dos relacionamentos humanos e assim enxergar outras possibilidades. Construindo a história da cidade, a maneira como mulheres e homens escolhem comportar-se ao resolver desafios que inevitavelmente surgem na vida em sociedade, mostra-se um modelo ético (entre outros) no processo educativo, na construção do ser humano. Nesse sentido, aprende-se a afetividade coletiva, a experiência de cuidar do outro, ajudar o outro, construindo um sentido de bondade e de justiça que se mostram nas ações mutuamente balsâmicas, nas trocas afetivas.

Paradoxalmente, constroem-se também a possibilidade de inflação do ego, a vaidade exacerbada, a arrogância que diminui a autocrítica. Desde alguns anos, o cinema prevê um futuro para a humanidade, com imagens de zumbis andando solitários pelas ruas das cidades, parasitas prontos para devorar o outro sem dar nada em troca em um mundo onde ter ou não ter segurança pública, ter ou não ter esperança ou o que consumir, não importa mais.

Definitivamente, promover as habilidades dos Sujeitos em ações e mudanças atitudinais que atendam às necessidades de vida digna para o maior número de pessoas, é uma escolha social e prática cultural de princípios éticos que se realiza na história da gestão da cidade, repercutindo sobre o comportamento das pessoas, em maior ou menor medida, dependendo das escolhas feitas por cada indivíduo, enquanto ele (ela) deseja participar acreditando na construção de outro tipo de cidadania, cuja inclusão humanitária e de outras espécies, trata de outra liberdade, edificando a compreensão em meio a incertezas e a outra gestão do futuro da cidade, mais tranquila, justa e bela. 


\section{ETHICS IN CULTURE AND IN CHOICE}

\begin{abstract}
This essay aims to reflect on the city administration and the preservation of organizational cultural practices that legitimate actions in the dynamics of ethical culture. The choices specif-ically made by the family and the impact on vulnerability of the citizen's security in the city are analyzed here. The theoretical reflections resort to Michel Serres (2003, 1997a, 1997b, 1990) on citizenship and ethics and the parasite on society; the methodology and theory to analyze the cultures of Gilbert Durand (2008, 2002); the mythical hermeneutics as proposed by Marcos Ferreira-Santos (2004), a parameter for social and hermesian, mediative education-al practices, and the mythical-hermeneuthics studies and researches made by Janina Sanches on interculturality in education (2010a; 2010b; 2011). Among the results found, on one hand, were the institutional, social, political pressures on family responsibility and morality; and, on the other hand, the symbolism expressed in the dynamics of culture, practices trivialized as ethical principles as well as a naive look in building citizenship and the type of perception of responsibility on account of the consequences of the choices made.
\end{abstract}

Keywords: City Management. Ethics. Culture. Citizenship.

1 Os resultados foram apresentados no $\mathbf{X X}$ Congresso International Szondi Association, realizado de 14 a 17 de julho, 2014, na Bélgica, com autoria de Janina Sanches e Clara Juareza Pereira, título "Szondi in Education: ethics in culture and in choice".

\section{REFERÊNCIAS}

BAUMAN, Zygmunt. Confiança medo na cidade. Rio de Janeiro: Jorge Zahar, 2007.

DURAND, Gilbert. Ciência do homem e tradição: o novo espírito antropológico. São Paulo: Triom, 2008.
As estruturas antropológicas do imaginário: introdução à arquetipologia geral. São Paulo: Martins Fontes, 2002.

FERREIRA-SANTOS, Marcos. Crepusculário: conferências sobre mitohermenêutica e educação em Euskadi. São Paulo: Zouk, 2004.

O crepúsculo do mito: mitohermenêutica \& Antropologia da Educação em Euskal Herria e Ameríndia. 2003. 540f. Tese (Livre docência em Educação) - Faculdade de Educação, Universidade de São Paulo, São Paulo, 2003.

GUGGENBÜHL-GRAIG, Adolfo. O Inválido. In: DOWNING, Christine (Org.). Espelhos do self: as imagens arquetípicas que moldam a sua vida. 1998. Disponível em: < http://groups. google.com/group/digitalsource>. Acesso em: 22 set. 2015.

MORIN, Edgar. O método 6: ética. 3. ed. Porto Alegre: Sulina, 2007.

SANCHES, Janina. Szondi in Education and about the femenine. In: CONGRESS OF THE IN- TERNATIONAL SZONDI ASSOCIATION, 19., 2011, Nice. Acta XIXth Congress of the International Szondi Association. Université de Nice Sophia Antipolis. Zurich: STIF-TUNG SZONDI INSTITUT, 2011. p. 281-302.

- Mitohermenêutica do feminino na antropologia da educação: interculturalidade Brasil-Peru. 2010. 202 f. Pós-doutorado. (Pós-doutorado em Filosofia da Antropologia da Educação) - Universidade de São Paulo, São Paulo, 2010a.

. Contact and ressentment are challenges to education enhancement. In: ALTEN-WEGER, Alois. Szondiana zeitschrift für schicksalsanalyse und beiträge zur tiefenpsy-chologie. Zürich: Versus Verlag, 2010b.

SERRES, Michel. Le parasité. Paris: Hachet- 
te Litteratures, 1997a.

Diálogo sobre a ciência, a cultura e o tempo. Conversas com Bruno Latour. Lisboa: Instituto Piaget, $1997 \mathrm{~b}$.

- Hermes: uma filosofia das ciências. Tradução Andrea Daher. São Paulo: Graal, 1990.

. Hominiscências: o começo de uma outra humanidade? Tradução Edgard de Assis Carvalho, Mariza Perassi Bosco. Rio de Janeiro: Bertrand Brasil, 2003.

SZONDI, Lipot. Tratado del diagnostico experimental de los instintos. Madrid: Biblioteca Nueva, 1970. 